\title{
A ÁRVORE DA VIDA COMO METÁFORA DO GÓTICO EM ERNST BLOCH
}

\author{
Ubiratane de Morais Rodrigues ${ }^{1}$
}

\begin{abstract}
Resumo
O objetivo deste artigo é apresentar o gótico como um dos conceitos norteadores da estética de Ernst Bloch. Para tanto, defendemos a hipótese de que o gótico surge no Espírito da utopia não só como oposição ao estilo egípcio e ao estilo grego, mas como oposto à frieza do mundo europeu do século 20 sustentada pela utilização da técnica em prol exclusivo do capital, portanto, do lucro, assim como potência estética a partir da metáfora da árvore da vida em $O$ princípio esperança. Pois, enquanto no Egito temos a vontade de se tornar como pedra, na Grécia temos o império do belo e do harmonioso, características de uma cultura ligada à estaticidade. Este diagnóstico faz Bloch perceber no gótico o surgimento de um espaço para a vontade utópica artística transgressora da inércia e da rigidez da pedra. Para melhor compreensão desta hipótese, apresentaremos a recepção do Espírito da utopia assim como sua transformação interna entre as edições de 1918 e 1923.
\end{abstract}

Palavras-chave: Gótico. Estética. Espírito da utopia.

\section{THE TREE OF LIFE AS METAPHOR FOR THE GOTHIC IN ERNST BLOCH}

\begin{abstract}
The objective of this paper is to present the gothic as one of the guiding concepts of Ernst Bloch aesthetics. Therefore, we defend the hypothesis that the gothic appears in the Spirit of utopia not only as an opposition to the egyptian style and the greek style, but as opposed to the coldness of the 20th century european world sustained by the use of technique for the exclusive benefit of capital, therefore, of profit, as well as aesthetic power based on the metaphor of the tree of life in The principle of hope. For while in Egypt we have the desire to become like stone, in Greece we have the empire of beauty and harmony, characteristics of a culture linked to static. This diagnosis makes Bloch perceive in the Gothic the emergence of a space for the utopian artistic will that transgressed the inertia and the rigidity of the stone. For a better understanding of this hypothesis, we will present the reception of the Spirit of utopia as well as its internal transformation between the 1918 and 1923 editions.
\end{abstract}

Keywords: Gothic. Aesthetics. Spirit of utopia.

\section{Espírito da utopia: recepção e reestruturação interna da obra}

Para melhor compreensão do gótico na estrutura de Espírito da utopia, far-se-á a seguir uma exposição da recepção desta obra e sua transformação interna. O Espírito da utopia causou várias polêmicas desde sua pré-publicação. Max Weber, por exemplo, mesmo sendo

1 Doutor em Filosofia pela Universidade de São Paulo (USP) na linha de pesquisa Estética e Filosofia da Arte com Bolsa da Fundação de Amparo à Pesquisa e ao desenvolvimento Científico e Tecnológico do Maranhão FAPEMA, Mestre em Filosofia na linha de pesquisa de Ética pela Universidade Estadual do Ceará (UECE) e Graduado em Filosofia pela Universidade Federal do Maranhão (UFMA). Atualmente é Professor Adjunto II de Filosofia da Universidade Federal do Maranhão (UFMA) Campus de Grajaú. E-mail: ubiratanerodrigues@gmail.com. 
próximo e tendo contribuído para a publicação da obra, não lhe poupou críticas, principalmente por suas imprecisões e sua estrutura ${ }^{2}$. Após a publicação vieram outras críticas, entre elas as de Max Scheller, Leo Löwenthal, Th. W. Adorno e Walter Benjamin. Destes dois últimos, a crítica era também um reconhecimento do valor da obra e do autor. Adorno em sua obra Notas sobre literatura escreveu que o livro Espírito da utopia influenciou significativamente sua escrita e pensamento, tanto que visitou Bloch em Berlim aos 18 anos de idade expressando-lhe grande admiração, reconhecendo anos depois a influência de Bloch em seus escritos e pensamento ${ }^{3}$. Benjamin expressou em uma carta que esta obra é o único escrito filosófico de sua época com o qual ele podia se medir ${ }^{4}$ mesmo fazendo duras críticas ao livro.

Faz-se necessário, para além das críticas, compreender esta obra em seu momento histórico e na sua plasticidade. Ela surge no delicado momento entre as duas guerras mundiais; todavia, não é um livro sobre a guerra ou a paz, também não é um livro sobre a geração de Bloch ou sua época. Como nos diz Jean-Michel Palmier, o Espírito da utopia "é um livro que fragmenta os gêneros, mistura filosofia e música, estética e política, filosofia e poesia. É a constatação da agonia de um mundo [...]" (PALMIER, 1985, p. 262, tradução nossa); e ao mesmo tempo o livro "foi a primeira tentativa de Bloch de uma fusão utópica que combinou a crítica da cultura expressionista dirigida contra o frio mundo externo do capitalismo, com uma renovação filosófica do utopismo e do messianismo revolucionário" (HUDSON, 1982, p. 07, tradução nossa).

Em 1923, o Espírito da utopia ganhou sua segunda edição ${ }^{5}$. Bloch organizou melhor os temas e apresentou seu pensamento mais sistematizado. Na nota da segunda edição,

2 Cf. BOURETZ, 2011, p. 692. Quanto a esta relação entre Bloch e Weber sobre a publicação do Espírito da utopia, são esclarecedores os comentários de Eva Karadi, que desenvolve ainda uma crítica sobre a diferença de tratamento de Max Weber em relação a Lukács e Bloch. "A maneira como Weber percebeu o Espírito da utopia é revelado em uma de suas cartas a Margarete Susman. Ele escreveu que ele tinha contribuído - não sem alguma relutância - para que a editora recebesse bem do livro de Bloch. Sua impressão era de que o livro continha, além - de um lamentável palavreado sem valor - coisas preciosas. Weber alega ter grande indulgência pela originalidade de Bloch, e isso com justa razão; mas a falta de forma, o caráter pretensioso - e a falta de maturidade -, que caracterizavam passagens importantes, o haviam revoltado a ponto de fechar o livro sem poder terminá-lo. Weber contribuiu para a publicação do livro por conta da 'filosofia da música'; por isso ele teria feito por carta ao editor." (KARADI, 1985, p. 73, tradução nossa).

3 Segundo Adorno: "O livro, o primeiro de Bloch e portador de todos os posteriores, produzia em mim uma revolta única contra a renúncia que se prolonga no pensamento, até em seu caráter puramente formal. É por isso que, antes de todo o conteúdo teórico, apoderou-se de mim a tal ponto que eu creio não ter escrito nada que, latente ou abertamente, não diz respeito a ele.” (ADORNO, 2003, p. 538, tradução nossa).

4 Carta a Gerson Scholen de 19 de setembro de 1919. Pode-se ler parte dessa carta em MÜNSTER, Arno. Utopia, messianismo e apocalipse nas primeiras obras de Ernst Bloch. op. cit., p. 158, nota 88. Para uma leitura da relação Bloch-Benjamin Cf. (Maciel, 2019) e (BOURETZ, 2011, p. 696).

5 Na entrevista a José Marchant, Bloch fala da constituição do livro Espírito da utopia, e acena que existem apenas três edições do livro; entretanto, não detalha os motivos pelos quais foram suprimidas partes da obra e acréscimos. Contudo, é enérgico ao responder sobre as alterações do livro: "Em 1923, o livro foi republicado 
ele diz que esta versão é a definitiva e sistematizada, enquanto a edição de 1918 fica como um projeto temporário, mesmo mantendo a primeira edição do livro no volume 16 das obras completas editadas pela Suhrkamp Verlag, reafirmando a importância desta em seu pensamento filosófico. De fato, entre as duas edições há um movimento interno na reorganização da obra, assim como um amadurecimento intelectual de Bloch, além da relevância filosófica das diferenças entre elas ${ }^{6}$.

O estudo minucioso de Ivan Boldyrev é esclarecedor neste ponto. Para ele, a comparação entre as três edições do Espírito da utopia nos ajuda a compreender o trabalho filológico e o conteúdo textual (Textbestandes) no contexto histórico-filosófico, assim como nos garante uma caracterização mais precisa da evolução do pensamento filosófico de Ernst Bloch. As reescritas para essas edições, principalmente a de 1964, momento em que o pensamento de Bloch já era maduro e completamente identificado ao marxismo, não interferiram no conteúdo do livro como um todo. Segundo Boldyrev,

Do ponto de vista do conteúdo, pode-se afirmar que a revisão do texto quase não teve consequências para o sentimento 'místico' inicial do livro. Não se deve afirmar que Bloch queria renunciar a seus pontos de vista anteriores e refazer seu texto em termos marxistas. Religiosidade, referências à Cabala e à Alquimia, assim como um tom profético-místico, permanecem intocados na $2^{\mathrm{a}}$ e na $3^{\mathrm{a}}$ versão (BOLDYREV, 2012, p. 54).

O trabalho de Bloch nas três edições ${ }^{7}$ de Espírito da utopia está diretamente ligado ao método da montagem (Technik der Montage), recurso este que ele não abandona, mas

em uma nova edição; do ponto de vista do conteúdo, nada foi mudado, absolutamente nada, mas acrescentei algumas passagens e outros parágrafos do livro foram estilisticamente retrabalhados. Eu adicionei, entre outros, uma parte política dedicada à atmosfera do pensamento da época, a guerra mundial de 1914 e os alemães. Descartei vários capítulos lógicos que foram publicados mais tarde, também por Paul Cassirer, em Berlim, sob o título 'Através do deserto'. Esta segunda edição serviu de base para a versão muito pouco modificada, contudo mais clara [...]" (BLOCH, 2016, p. 59-60, tradução e grifo nossos). Entre os capítulos que foram suprimidos temos "Símbolo: os judeus", publicado na França com um excelente estudo como introdução por Raphaël Lellouche, e o "Herói cômico" que trata de Dom Quixote, analisado neste capítulo. Há ainda um trabalho minucioso comparando as alterações nas edições do Espírito da utopia: (BOLDYREV, 2012, p. 3254). Para conferir em português esta análise: (BOLDYREV, 2019, p. 137-162). Conferir ainda a nota 1 feita em (COPPELLOTTI, 2004, p. 7).

6 Para R. Lellouche, a mais significante mudança foi a retirada do capítulo "Símbolo: os Judeus". Ele compara esse texto escrito em 1912 com o texto "misticismo judaico" de Lukács, que este nunca traduziu para o alemão nem o reescreveu. Ainda segundo ele, "a diferença entre as duas edições é filosoficamente relevante na evolução intelectual de Bloch, ela vai muito além de uma simples redução da quantidade de textos, há modificações e inflexões de certos conceitos, a supressão de capítulos ou o rompimento do acordo das partes, a acentuação diferente de certas passagens e em particular a reescritura ampliada da introdução [...]." (LELLOUCHE, 2009, p. 28, tradução nossa).

7 Ainda sobre as duas primeiras edições, Raphaël Lellouche sustenta que o acontecimento da revolução da Baviera, entre novembro de 1918 e 3 de maio de 1919, um acontecimento relevante entre as duas edições, cujo fim trágico é um dos fatores para a retirada do capítulo "Símbolo: os Judeus" da edição de Geist der Utopie posterior a 1918. O que para nós não parece ser o único motivo, mas uma questão lógica-estrutural da obra

\begin{tabular}{|c|c|c|c|c|}
\hline Rovita Alolectus & Ano 10 & n. 21 & Janeiro - Abril 2021 & p. $226-244$ \\
\hline
\end{tabular}


aperfeiçoa em sua jornada filosófica. Malgrado as supressões de textos, eles não se perdem; Bloch os recuperou em edições de livros posteriores, como, por exemplo, o capítulo $O$ herói cômico, que aparecerá com mais força teórica e poética em $O$ princípio esperança. No que diz respeito à importância filosófica das diferenças internas entre as duas primeiras edições da obra, destaca-se que é na edição de 1923 que aparece pela primeira vez a teoria do ainda-nãoconsciente (Noch-nicht-Bewußten), um conceito importante do pensamento de Bloch na engrenagem da esperança, sem o qual a utopia concreta é impossível. Nesse período, de 1923, ele está mais próximo do marxismo, e sua leitura de Luta e consciência de classe de Lukács de 1923 “[...] sugere que ele estava tentando uma fusão sistemática de sua filosofia utópica com o marxismo" (HUDSON, 1982, p. 08, tradução nossa). Há ainda a influência do pensamento de Nietzsche $^{8}$, a quem Bloch dedica, inclusive, um tópico na edição de $1918^{9}$. Sobre esta influência, entre outras coisas, ele desejava principalmente buscar as raízes do niilismo denunciado por Nietzsche; raízes essas que ele buscou entender, e superar, a partir da filosofia de Kant e Hegel, pelo menos nas formas de visão de mundo implicadas nesses pensamentos. Assim, não é só o pensamento místico de Eckhart, Böhme, Dostoiévski, Paracelso e outros que influenciaram o Espírito da utopia, tampouco só as correntes artísticas e culturais de seu tempo, mas também uma dose significativa da filosofia alemã.

O Espírito da utopia não é uma história da utopia com uma descrição de possibilidades utópicas outras. Bloch, com seus fragmentos e estilo único de escrita, cuja potência filosófica ardia junto às revoltas artísticas das vanguardas, iniciou um resgate das imagens do passado que não foram realizadas, mas que poderiam ser atualizadas no presente por suas energias utópicas. A arte e principalmente a música são nesta obra e em $O$ princípio esperança o lugar próprio da manifestação utópica do homem no mundo. O Espírito da utopia necessita do espírito que ainda está em gérmen no passado não realizado; nesse sentido, é importante observar que faz parte do método de Bloch a constante reafirmação do utópico latente nas imagens do desejo no passado não liquidado e que ainda hoje possuem a força utópica em si. Por essa força utópica, que também é protesto, no conteúdo e na forma, podemos

como um todo, como no caso de Dom Quixote, por exemplo, que não aparece mais em 1964 porque já encontrou seu lugar adequado em O princípio esperança, uma vez que no todo estrutural da obra de 1964 já não havia lugar digno para sua existência. Para uma compreensão mais detalhada deste momento histórico que influenciou significativamente filósofos alemães do século XX, como Ernst Bloch, Walter Benjamin e T. W. Adorno, Cf. (LOUREIRO, 2005).

8 Uma abordagem dessa influência é feita por Francesco Coppellotti na introdução da edição italiana do Espírito da utopia: (COPPELLOTTI, 2004).

9 Cf. (BLOCH, 1918. p. 267-270). 
concordar com a afirmação enfática de Jean-Michel Palmier: "acredito profundamente que a abordagem de Bloch no Espírito da utopia contém um sentido político revolucionário" (PALMIER, 1985, p. 260, tradução nossa.). Entretanto, esta obra não é um manual de filosofia política, ética ou estética; mas traz em si a potência filosófica capaz de mobilizar o pensamento em torno do humano e seu encontrar-se consigo mesmo no mundo.

No Espírito da utopia, Bloch se preocupou com o que podemos considerar uma perspectiva subjetiva da utopia. A fantasia e a criatividade na reinvenção do mundo exterior tinham suas raízes na compreensão adequada da interioridade, do obscuro instante vivido. Assim, ele lançava as bases de uma nova compreensão da subjetividade criativa utópica, e nesses termos, não lhe importava o ideal de uma sociedade perfeita já existente numa esfera espacial, com fez Thomas Morus, por exemplo, em seu livro Utopia. Para ele, as raízes do mundo exterior-melhor estavam arraigadas na alma do sujeito. Ele combatia, assim, o empirismo extremo de seu tempo de um lado e o subjetivismo vazio do outro. Essa era ainda uma questão-limite para Bloch, afinal, como sustentar uma viagem interior para construir o mundo como espelho da alma sem cair num idealismo vazio? Como a consciência pode se relacionar com o mundo exterior numa projeção para o melhor sem cair na vulgaridade de uma abstração utópica? Essas questões são centrais para compreensão do método de Bloch. Para isso, nosso filósofo lança mão de um recurso já utilizado pelo poeta Reinhold Schneider (19031958), por Walter Benjamin e pelo teólogo e filósofo Paul Tillich (1886-1965): a ligação direta entre utopia e escatologia,

[...] a fim de corrigir a imanência excessiva da utopia e a alienação do outro mundo da escatologia. Ele [Bloch] enfatizou a função de abertura das imagens escatológicas, e, em uma fusão do apocalíptico Judaico, do gnosticismo e do cabalismo e da escatologia de Franz von Baader, ele falou de 'escatologia universal ou auto-encontro' e de um apocalipse que seria o cumprimento de toda a gnose revolucionária (HUDSON, 1982, p. 08, tradução nossa).

Nesse sentido, seguindo Wayne Hudson, não só a mística foi transformada em metafísica, como Bloch, influenciado por Nietzsche, construiu um argumento de renovação das categorias filosóficas após o anúncio da morte de Deus. Esse anúncio não é uma motivação para o niilismo, mas um motivo para renovação filosófica num sentido positivo e, desse modo, a mística e a religião podem auxiliar, mesmo que seja para no fim se falar, por exemplo, de um ateísmo no cristianismo. Entre essas renovações filosóficas no pensamento de Bloch encontram-se a metafísica e o conceito de utopia. 
No que concerne à estética, destaca-se a análise importante dos conceitos de "vontade utópica e expressividade" ou "transparência" e "subjetividade criadora: Gênio" realizada por Arno Münster. Segundo ele, o conceito de vontade utópica não somente é central como categoria estética do Espírito da utopia, como também é influenciado diretamente pelas leituras religiosas e místicas que levaram Bloch a pensar o interiorizar-se “[...] para o conhecimento do próprio eu como um vetor para o auto desvelamento [...]” (MÜNSTER, 1997, p. 127). A filosofia do encontro consigo mesmo (Selbstbegegnung) que Bloch propõe tem sérias implicações para sua estética, pois ela cria a necessidade da "subjetividade criadora: Gênio" se manifestar enquanto produtora de obras utópicas. Este trabalho defende, desde o pensamento de Bloch, que tal subjetividade cria obras transgressoras dos limites epocais que aprisionam os sujeitos. Assim, manifesta-se uma contraposição entre a vontade dirigida para a transformação do mundo "[...] e a vontade interpretada como uma força que fermenta nas profundezas psíquicas do homem e do ser em geral [...]" (MÜNSTER, 1997, p. 127). Notar-se-á, entretanto, que a vontade utópica está ligada aos sonhos despertos, sonhar-para-a-frente, categoria esta que será o tema central de $O$ princípio esperança ${ }^{10}$. Desde sua primeira obra, ele já confiava nesse conceito como seu cavallo di battaglia. A passagem da vontade utópica para a vontade estética depende da conexão dos sonhos que impulsionam para frente, uma vez que a vontade estética no Espírito da utopia produz “"...] as configurações da 'coleção germinadora' como expressão da vontade de descrever os 'caminhos metafisicamente constitutivos' pelos quais nós nos introduzimos subjetivamente no 'verdadeiro e real' [...]" (MÜNSTER, 1997, p. 127).

É um movimento interior que se dirige para o exterior como revolta e protesto, mas também como ação. Assim, a vontade utópica é o lugar do nascimento dos sonhos despertos, e este, desde o Espírito da utopia, embora não desenvolvido, já é o lugar de nascimento das artes. A esse respeito, a tese de A. Münster sobre o cerne da estética blochiana da juventude é que: "tal definição apriorística da vontade utópica, como renúncia do subjetivo, ansioso, e como constante metafísica de um desejo estético universal, determina a doutrina da arte no Espírito da utopia" (MÜNSTER, 1997, p. 128). Essa tese se liga ao conceito da subjetividade criadora: o gênio. Este conceito no Espírito da utopia está próximo das teorias do gênio do Iluminismo, classicismo e próximas ainda da concepção do gênio nietzschiana. A concepção de gênio, todavia, tem dois momentos distintos na obra de Bloch: um no Espírito da utopia e outro em $O$ princípio esperança. Ambos os momentos são indissociáveis da problemática do pré-

10 “[...] o presente livro não trata de outra coisa que não o esperar para além do dia que aí está [...] O tema das cinco partes desta obra são os sonhos de uma vida melhor" (BLOCH, 2005, p. 21).

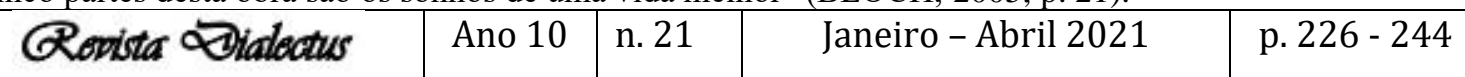


consciente, da juventude e dos sonhos diurnos em relação à produtividade artística. Adianta-se que para Bloch o conceito de gênio “[...] não coincide com a 'inteligência pura' kantiana [...] o conceito é novo, englobando a ultrapassagem do limiar - do inconsciente para o consciente, do não-eu para o eu - e o conceito de natureza, que comporta a ideia de um sentido em ebulição, 'que dá à luz"' (MÜNSTER, 1997, p. 130).

\section{Vertical interna: da necessidade do encontrar-se consigo mesmo (die Selbstbegegnung)}

O gótico no Espírito da utopia tem uma função imprescindível: apontar, na teoria estética do ornamento de Bloch, para uma vontade de transgressão de limites com sua vontade de ressurreição (Werdenwollen wie Auferstehen), pois seja no ornamento ou na arquitetura, no gótico há algo de metafísico e ao mesmo tempo concreto ${ }^{11}$. A análise de Bloch sobre o Eu, embora siga em direção ao encontrar-se consigo mesmo, não é uma análise puramente subjetivista do ornamento e da obra de arte, tampouco uma análise fria e empiricista dos artefatos como ornamento, nem da arquitetura ou da pintura como objetividades frias. No Espírito da utopia encontramos a dimensão da utopia ligada à arte. O percurso da estética nesta obra não é uma questão metodológica: ela parte do ornamento, da arquitetura, da pintura e da literatura (Dom Quixote) - esta parte retirada em 1964 - até chegar à música. Este movimento é uma concepção estética que acompanha Bloch desde sua juventude e faz parte da estrutura de sua filosofia. É o que encontramos também, com leve acréscimo, em $O$ princípio esperança. Faz-se necessário salientar que, mesmo não aderindo totalmente à divisão dos períodos da arte feita por Hegel em seus Cursos de Estética ${ }^{12}$, Forma de arte simbólica, Forma de arte Clássica e Forma de arte Romântica, Bloch faz esse mesmo percurso em sua fundamentação do encontro consigo mesmo: arte egípcia, arte grega e arte gótica, como uma espécie de recuo para romper com a frieza técnica de seu tempo, que operava inclusive na estética.

A análise estético-filosófica de Bloch está marcada pela voracidade com que as vanguardas artísticas históricas puseram em xeque a arte institucional e pela força transgressiva e utópica com que ele articula seus conceitos e ilustrações. Salienta-se que sua crítica extrapola o quadro unívoco da arte, passa ao sociológico-histórico e econômico, criticando duramente

11 "A estética do ornamento no sentido metafísico implica, ao mesmo tempo, a consideração da arte como um encontro consigo mesmo (Selbstbegegnung), em que a obra de arte realiza na prática o ato de liberdade produtivo e criativo que antecipa (Vorschein) aquela metaforização da realidade como um prelúdio para a transformação da condição humana e que atinge aquela 'pátria' (Heimat) que a todos brilha na infância e que inda-não-foi” (COPPELLOTTI, 2004, p. XXIX.).

12 Cf. HEGEL, G. W., 2001, p. 86-103.

\begin{tabular}{|l|l|l|l|l|}
\hline Qevista Dialectus & Ano 10 & n. 21 & Janeiro - Abril 2021 & p. $226-244$ \\
\hline
\end{tabular}


“[...] a obsessão estilístico-decorativa e a introdução da máquina na arte. Pode-se dizer de antemão que o seu pensamento está em polêmica aberta tanto contra os excessos de estilo e dos estilos do passado como contra a ilusão de conciliar arte com indústria" (MACHADO, 2001, p. 36).

O início do percurso para o encontrar-se consigo mesmo tem de saída uma certeza: "Eu sou. Nós somos" (Ich bin. Wir sind) (BLOCH, 1964, p. 11). Certeza esta que não remonta ao racionalismo cartesiano, segundo o qual se pode partir para o mundo depois da certeza indubitável da existência de si pela descoberta do cogito ergo sum, mas constitui um alerta imediato de que "agora temos que começar" (Nun haben wir zu beginnen) (BLOCH, 1964, p. 11). Geist der Utopie nos impõe uma condição de ação, uma atitude diante do mundo. O vazio é o espelho das primeiras décadas do século 20, vazio entre as duas grandes guerras mundiais, no meio da destruição, dos questionamentos sobre a técnica e o humano, e, ao mesmo tempo, ao se vislumbrarem novas possibilidades sociais e técnico-científicas. Mas o Espírito da utopia, ao contrário de sua época, não é vazio de sentido, não destila doses de niilismo num mundo já desesperançado, mas é justamente contra o niilismo e o irracionalismo europeu que podemos ler uma das tantas vertentes dessa obra, pois desde o início do livro o imperativo é claro: precisamos assumir a vida que nos foi posta na mão. O protesto inicial e recorrente na obra é contra a mediocridade dos intelectuais de seu tempo, contra o capitalismo, que torna tudo obsoleto e insignificante, contra o luxo, contra o militarismo e contra toda sorte de rebaixamento do humano.

Se sua linguagem é mística e expressionista, não deixa por isso de ser filosófica. Bloch fala outramente do estado de coisas atual, fala outramente da realidade para não ser pego no laço do intelectualismo, do representante intelectual que tem a resposta pronta para os problemas do mundo; assim, ele afirma que: “[...] as universidades se tornaram verdadeiros cemitérios do espírito, repletos do fedor da podridão e do obscurantismo da rigidez" (BLOCH, S/D, p. 02). Por isso Bloch, ao dizer "Ich bin. Wir sind", embora isso não nos dê muita vantagem, ou vantagem nenhuma, diz imediatamente: "Das ist genug” (isso é o suficiente), pois precisamos começar pela interioridade e rever os conceitos e paradigmas de um mundo em que parece não haver mais instituições confiáveis, onde os valores agora são de outra ordem que não a do humano e do bem: mas a do lucro. O início então é pelo encontrar-se consigo mesmo (Selbstbegegnung), que é também um encontrar-se na existência concreta do mundo, entre coisas, pessoas e eventos. É o que ele chama de uma descida, uma vertical interna (interne 
Vertikale) que fará aparecer o mundo da alma (die Welt der Seele). Pode-se assim entender a relação que Bloch estabelece entre interioridade e exterioridade, entre utopia e sonhos diurnos.

[...] a função externa, cósmica da utopia, contraposta à miséria, à morte, e ao reino oco da natureza física. É tão-somente em nós que brilha ainda essa luz, e o trem fantástico em direção a ela tem início, o trem para a interpretação do sonho lúcido, para a manipulação do conceito em princípio utópico (BLOCH, S/D, p. 04).

O caminhar no mundo em busca de si tem no meio da cotidianidade seu locus; o início é entre as coisas mais simples, como, por exemplo, um jarro velho. O encontro consigo mesmo tem o início inquieto de não sabermos do instante em que vivemos, esse agora que nos foge, inquietude que levou o Fausto de Goethe a fazer a aposta com Mefistófeles pelo instante plenificado, por exemplo. A arte, nesse sentido, surge como o primeiro lugar do encontrar-se consigo mesmo. Bloch passa de uma aparente e ingênua relação entre o eu e um jarro, seja como artefato importante nas culturas, seja por sua função prática e simbólica, até a música, onde se experimenta a profundidade interior do eu. Este movimento blochiano, para além do conteúdo, possui uma beleza incomum, como assinalou Jean-Michel Palmier, beleza essa que “[...] é sem dúvida devido à sua forma elíptica, misturando gêneros, passando sem transição da reflexão sobre um simples jarro, um objeto qualquer, para a filosofia da arte" (PALMIER, 1985, p. 264, tradução nossa).

O capítulo sobre um jarro antigo tem uma função existencial, estética e paradigmática. Existencial porque coloca o ser humano no centro de sua inapercepção do instante vivido, examina o existir ali, onde a cotidianidade só é conhecida/compreendida $a$ posteriori; estética porque o jarro é um artefato, uma obra, possui função e beleza, mesmo que não perceptível, portanto, estética no sentido da percepção daquilo que vibra enquanto nos atira de volta ao interior; e paradigmático por representar uma ruptura com a estética do luxo. Nesse sentido Th. W. Adorno foi quem melhor percebeu a relação crítica entre o Jarro velho de Bloch e A asa do vaso de Georg Simmel. Enquanto o velho jarro de Bloch está imerso no mundo cotidiano da vida entre as coisas, como artefato e obra de arte, Simmel vê a separação entre a obra de arte e a vida cotidiana. Em Notas de literatura, no capítulo A alça, a jarra e a primeira experiência, Adorno aponta as discordâncias entre Bloch e Simmel. Na análise de Bloch no Espírito da utopia, seu jarro velho não possui as marcas de diferenciação que lhe permitem a insígnia da alta cultura como objet d'art. O jarro velho ao contrário da jarra de Simmel, não tem alça, é “[...] um jarro que não mantém com o mundo da utilidade uma comunicação tão 
fluida quanto a que inspirou as observações de Simmel" (ADORNO, 2003, p. 539, tradução nossa).

O mundo da utilidade e o mundo da beleza estão separados para Simmel. A obra de arte constitui para ele um espaço ideal. Adorno percebe isso não só no conteúdo da exposição de Simmel e em sua reflexão sobre os objetos que habitam a cultura, como no próprio escrito sobre $a$ alça, em que não são apresentados utensílios cotidianos em seu conteúdo. Segundo Adorno, neste ensaio de Simmel "[...] só se fala de objets d'art agradáveis, nada pré-histórico é digno de sua seletiva atenção, a filosofia de Simmel se serve, como Brecht costumava dizer de todo gosto refinado, do estilo de prata; a fibra do pensamento se capitula diante da arte decorativa" (ADORNO, 2003, p. 542, tradução nossa). Simmel, em sua análise sobre a alça, fala de artefatos que agradam e apetecem aos olhos, ao contrário do jarro de Bloch, que está no meio da cotidianidade, proporcionando ao humano o encontrar-se consigo mesmo. Não há distância aqui entre o artefato e o homem, não há na beleza da forma do jarro um ocultamento do humano.

A opção de Bloch pelo jarro de forma rústica está ligada à sua experiência com o expressionismo alemão, mais especificamente com o grupo Der Blaue Reiter ${ }^{13}$. Nesse sentido, "parece" paradoxal a análise de Bloch sobre o velho jarro quando diz que este, não tendo nada de artístico em si, é referência para a obra de $\operatorname{arte}^{14}$. A questão em jogo é a relação entre forma e conteúdo, e a primazia deste último, que Adorno percebeu comparando Bloch a Hegel, uma vez que para ambos aquilo que mais importa é o conteúdo da obra: "o que é belo para ele [Bloch] não são as proporções de seu jarro, mas o que, em termos da sua evolução e de sua história, tem acumulado nele, o que desapareceu dele e o olhar do pensador, tão delicadamente como agressivamente desperta para a vida" (ADORNO, 2003 p. 543, tradução nossa). Adorno marca no Espírito da utopia esta polêmica que Bloch estabelece com a alça de Simmel; o jarro para Bloch ${ }^{15}$ é Eu mesmo, como salientou Adorno, o reconhecimento de si no jarro. Essa relação entre o utensílio cotidiano e o humano que desperta o primeiro movimento do encontrar-se

13 Para mais detalhes sobre a relação de Bloch com o Grupo expressionista Der Blaue Reiter (O Cavaleiro Azul) formado em 1911 em Munique na Alemanha, conferir, entre outros: (PALMIER, 1978; MÜNSTER, 1997 e MACHADO, 2016).

14 Cf. (BLOCH, 1964, p. 19).

15 Nas palavras do próprio Bloch: “[...] um velho jarro que eu olho, e quanto mais eu olho para esse velho jarro, mais posso tomar a forma de um jarro. Uma poça não me tinge de cinza, um corrimão não me dobra, mas posso tomar a forma de um jarro. E é isso que acontece com o motivo ornamental que se encontra no jarro, no antigo jarro de Bartman, produzido na Renânia por volta dos séculos XVI e XVII. É nesse jarro que o encontro-de-simesmo se realiza pela primeira vez, se expõe, por assim dizer, na loja, em exposição na prateleira, na vitrine." (BLOCH, 2016, p. 53, tradução nossa)

\begin{tabular}{|l|l|l|l|l|}
\hline Rovista Dialectus & Ano 10 & n. 21 & Janeiro - Abril 2021 & p. 226-244
\end{tabular}


consigo mesmo é o tom que marca o caminho transgressivo até as figuras-modelos da transgressão (Fausto e Dom Quixote) e da música como linguagem da espera por excelência.

\section{Alma quente, mundo frio: considerações sobre a frieza da técnica}

A frieza do mundo e a frieza da técnica, que contaminam utensílios cotidianos, o produtor, o consumidor e o artista são um empecilho no caminho do Eu para encontrar-se consigo mesmo. Por isso, não só o frio dos utensílios, mas também a frieza no interior das construções deve ser denunciada e combatida. Um dos principais alvos de Bloch é a pura racionalização do mundo, a técnica pela técnica. Sua pergunta pelo ser novamente dos utensílios quentes remonta à interioridade dos espaços, ao humano reduzido ao interior arquitetônico social e à frieza do mundo. Nestes termos, a máquina não só esfria as coisas, mas é responsável pela "[...] miséria e morte da fantasia, que penetra na consciência, que coage qualquer museu a tomar como encerrada a existência de artesanato dos últimos quarenta anos do século passado" (BLOCH, S/D, p. 09). Sem a fantasia, as coisas são sem vida, e, nesse sentido, sua crítica não deixa de ser irônica quando nos remete ao ornamento reduzido a objetos decorativos de banheiros. Importante salientar que denunciar esta frieza e a destruição da fantasia não é em hipótese alguma uma recusa incondicional da técnica, como observou Carlos J. Machado: "a recusa da técnica não é abstrata, é dada pela sua utilização e simplesmente não aceita uma reconciliação entre arte e máquina" (MACHADO, 2001, p. 39). No contexto de crítica e reflexão, Carlos J. Machado lembra que é nesse momento que temos em Bloch o conceito de racionalização-reificação (Sachlichkeit), e aponta que é a Max Weber que Bloch dirige sua crítica contra a racionalização na esfera da vida, “[...] no caso da arte, isto significa uma racionalização-reificação tanto da espacialidade como da temporalidade, em sentido bem próximo daquela crítica da reificação elaborada por Lukács em História e consciência de classe” (MACHADO, 2001, p. 40-41).

Não há mais espaço para os antigos artesãos no século XX, o mundo do capitalismo necessita de lucro rápido, o "progresso" aniquilou o tempo da produção artesanal, produzindo a alienação no trabalho. Não há mais alegria no esforço para o homem que não vê mais o todo de seu labor. Nosso filósofo pensa uma técnica diferente, humanista e não para o lucro, que deveria ser "[...] inventada para fins inteiramente outros, puramente funcionais, sem qualquer amadorismo na produção de bens e sem qualquer substituição maquinal de produtos anteriormente artísticos: [...]" (BLOCH, S/D, p. 10). A crítica de Bloch ao que ele chamou de 
tenebrosa desertificação (grauenhafte Verödung) é decorrente desta técnica que automatiza o mundo e consequentemente o humano. Este último devia ser liberado do sofrimento e desenvolver sua capacidade criativa em sua totalidade, mas ocorre justamente o contrário: um aprisionamento e uma simbiose máquina-humano-máquina. Não obstante, como já se disse, não há em Bloch uma negação da técnica em si, nem da máquina como instrumento, mas sim das suas consequências: automação e fetichização. Não se trata de voltar ao passado, pré-revolução industrial, mas postular uma técnica humana, capaz de possibilitar uma subjetividade latente que aspire sempre ao melhor, que queira sempre a expressão de sua alma no mundo, tanto no cotidiano prosaico como no campo da arte.

As reflexões sobre os ornamentos frios, sem vida e sem humanidade, não são apenas críticas ao mau gosto produzido pela frieza da técnica, mas a busca da emancipação do humano e da arte, distanciando essa última de uma simples funcionalidade decorativa. Uma vez que Bloch reconhece a importância da técnica para a humanidade, a máquina é apenas uma ligação de uma cadeia, e a responsabilidade do fracasso ou da esperança é

[...] meramente o fenômeno de um espírito puxado para a frente, ameaçado, talvez evadido para círculos mais amplos; as condições de possibilidade da máquina e seu emprego puro, são, por fim, de espécie da filosofia da história e se encontram estreitamente vinculados às condições da possibilidade de um expressionismo antiluxuriouso (BLOCH, S/D, p. 10).

Assim, contra a frieza da técnica e da máquina, contra o unicamente útil, Bloch quer uma liberdade na expressão. Ele quer tempo livre para a criação, assim como as crianças que sem a preocupação da funcionalidade maquinal da expressão agem em seus desenhos. Ele cita dois expressionistas para se referir a este paradigma: Paul Klee e Franz Marc. O expressionismo tem essa exuberância “infantil”" que as máquinas não podem forjar. Ele reivindica uma arte cuja expressão tenha o sentido de algo maior, para além do funcional e do meramente decorativo e comercial. Com isso, Bloch se mostra um defensor da autonomia da arte desde os caminhos abertos por Paul Klee e os expressionistas do grupo de Franz Marc. A relação entre técnica e arte requer uma interdependência em que artista e obra sejam autônomos um em relação ao outro e ambos autônomos em relação à coisificação maquinal. A busca da expressão nua e crua (der geistigen Direktheit) era fim e meio da revolta instalada no seio do expressionismo em seu nascimento, segundo Bloch, essa vontade utópica de expressão nua e crua leva a arte a permanecer distante da utilidade e negar

[...] a vocação do inferior do gosto, da configuração estilística da vida inferior voltada ao bem estar; agora reinava a grande técnica, um 'luxo' para todos, mais aliviador, 
mais insensível, mais espirituoso, mas democrático, a reconstrução do planeta terra com o objetivo de erradicar a miséria, de transferir para a máquina o esforço, de centralizar e automatizar o inessencial, e possibilitar com isso o ócio; e predomina agora a grande expressão, tendo o adereço se movido novamente nas profundezas, garantindo puros signos da compreensão, puros ornamentos da resolução, para afirmar o interior sobre o silenciamento das preocupações externas (BLOCH, S/D, p. 13, grifos do autor).

Isto equivale a dizer que Bloch está preocupado com a emancipação da arte, com sua autonomia, e, em decorrência disso, o ornamento se tornaria libertador. Expressão autêntica, viva e ressurreta, é isso que Bloch quer no ornamento, e é isso que ele encontrará no estilo gótico. Nesse sentido, a confrontação entre o útil funcional e a exuberância tem como marca a arquitetura. A citação acima nos esclarece ainda quatro pontos, a saber: Bloch não é contra o ornamento; não é contra a técnica; não é contra a máquina e aspira em sua filosofia da arte a uma expressão capaz de significar o mais profundo do humano: a liberdade. Seu antiornamentismo é “[...] no sentido do excesso decorativo, do velho luxo, da reutilização dos estilos do passado; sua aproximação da arte com a espontaneidade autêntica, com a expressão, é o contrário de qualquer dissolução da arte no cotidiano [...]" (MACHADO, 2001, p. 43). No que concerne à tese de A. Münster de que a estética de Bloch é uma estética da expressividade, Carlos J. Machado acrescenta que, rompendo com a racionalização-reificação existente na "alta cultura", com a qual não compactua, Bloch antecipou “[...] as tentativas de vanguarda do século voltadas para uma redefinição das relações entre arte e público, na qual a arte avançada se reintegra às expressões do cotidiano, sem, ao mesmo tempo, se dissolver e sem confundir o estético com o funcional ou vice-versa" (MACHADO, 2001, p. 43). Ademais, na busca pela expressão nua e crua que transgrida a reificação-fetichização do mundo, do humano e da arte, Bloch encontra no caminho de suas pesquisas a vontade de ressurreição do gótico.

\section{O mundo como espelho da alma: a árvore da vida}

Bloch parte do estilo grego para chegar ao gótico. Aquele, mesmo na forma da pedra, não tem o peso da matéria da obra, é um estilo plástico e a exuberância interior diante da pedra não aparece. Isso se deve ao seu modus vivendi, no qual o apolíneo impera e cuja aparência quer ser "[...] simultaneamente vivo e subjugado, empático e simétrico, pictórico e arquitetônico de uma vez, tornando-se assim 'plasticidade"” (BLOCH, S/D, p. 16). Além disso, o equilíbrio da força que move a expressão, não "[...] adquire nem expressão interior nem a violência de um espaço exterior" (BLOCH, S/D, p. 16). É o império do belo, do harmonioso como medida de uma moral interna expressa na leveza do mármore ditando o ritmo da vida 
grega. Essa vontade de harmonia e sedução livrou os gregos de uma visão caótica do mundo, e não só a harmonia entre os homens e o mundo, mas no mundo, entre o orgânico e o inorgânico, impedindo-os de alcançarem aquela grande exuberância que Bloch só encontrará no gótico.

Na busca da expressão pura e crua nosso filósofo avança sua análise para o estilo egípcio. Este ainda está próximo ao estilo grego no que se refere à forma funcional. Apesar disso, ele reconhece que a arte no Egito aparece em outra esfera relacional, numa profundidade maior, de onde surge segundo ele "[...] o espírito pétreo absoluto e uma geometria em última instância inamistosa se alcança materialmente como figuração do Egito, como o domínio total da natureza inorgânica sobre a vida" (BLOCH, S/D, p. 18). É no âmbito do necrótico que circula a intenção do estilo arquitetônico e ornamental dos egípcios: constrói-se para morrer. Bloch caracterizou a expressão egípcia como uma vontade de se tornar como pedra, onde a vida interior foi suprimida em prol de uma vida futura pós-morte, onde a rigidez da pedra e do inorgânico é o refúgio final daquele que se prepara para morte, vitória do inorgânico sobre o orgânico. Segundo ele, o silêncio é a característica da arte sacra egípcia, arte marcada pela morte e pela ausência de vida. Nosso filósofo caracteriza a vontade egípcia de ser como pedra, ao contrário da plasticidade do estilo grego, como um monstruoso fanatismo da rigidez (einem ungeheuren Fanatismus der Starre) em que temos uma harmonia entre a função e o estilo no caminho da vontade de ser como pedra.

Se no Egito e na Grécia ainda temos uma cultura ligada à estaticidade, é somente com o gótico que Bloch percebe o surgimento do espaço onde a vontade utópica artística transgride a estaticidade, a inércia e a rigidez da pedra. Se a vontade de expressão desde o início era posta na madeira e perdeu-se no caminho pela volumosidade da pedra ou do mármore, Bloch aponta uma simbiose entre a madeira e a pedra no gótico, pois a "vida interior" (innere Leben), não tem uma forma definida, estática, sua expressão no mundo é igualmente plástica. A madeira é um suporte mais obediente a esta vontade de ressurreição do que a pedra, ela permite as curvas, as sobreposições, ela permite a libertação da "essência interior" (innere Wesen), apontando para um lugar a que ainda não chegamos e não conhecemos. No gótico a retomada das linhas orgânicas "quase esquecidas" nas construções, nos ornamentos, sintetiza aquilo que veio antes dele, onde o orgânico e o inorgânico encontram harmonia.

Se agora em geral ainda é possível uma salvação por detrás dos estilos rejeitados e ultrapassados, então ela só pode ocorrer senão mediante uma retomada dessas linhas orgânicas quase inteiramente esquecidas. Tudo o que deve florescer e se tornar exuberante deve aprender com tais imagens pré-góticas, e não há nenhuma espiral, nenhuma digressão e nenhuma violência arquitetônica nas leis profundamente 
orgânicas dessa digressão que com a sua cabeça não respirasse também na atmosfera desse elemento orgânico, plena de selvagens pressuposições e infinitos, saturado de nuvens, ventoso, musical (BLOCH, S/D, p. 21).

No cerne deste debate evidencia-se a posição de Bloch contra Riegl e Worringer sobre a ornamentação, embora Bloch reconheça a importância dos ornamentos para a história da arte. Qual foi a tarefa de Bloch diante dessa teoria? Ele, “[...] tinha que se situar em uma história da arte, que, depois de Riegl, parece dar mais importância à ornamentação dos objetos de uso do que à grande arte" (MACHADO, 2001, p. 37). A. Münster aponta que o pensamento de Bloch está próximo das teorias estéticas de Riegl e de Wilhelm Worringer, proximidades que segundo ele estão no campo "[...] da revificação subjetiva e intuitiva do desejo estético arquitetônico [...]" (MÜNSTER, 1997, p. 129), e não na totalidade da teoria dos dois. Na exaltação do gótico com sua simbiose entre o orgânico e o inorgânico, Bloch encontra a exuberância da vontade de ressurreição. Enquanto o Egito caminha do interior para o exterior na forma da pedra, é misterioso e sem mistério ao mesmo tempo, o gótico ou a linha gótica não é inércia, mas

[...] possui o foco em si mesma; ela é destituída de repouso e lúgubre assim como as suas formas: os bocéis, as serpentes, as cabeças de animais, os cursos de água, um entrecruzar-se e oscilar desordenados, no qual se encontra o líquido amniótico e o calor de incubação e começa a falar o regaço de todas as dores, voluptuosidades, nascimentos e imagens orgânicas: apenas a linha gótica porta desse modo o fogo central em si mesma, no qual os seres orgânico e espiritual mais profundos são conduzidos ao mesmo tempo à maturidade (BLOCH, S/D, p. 22).

Estas são características pelas quais se pode diferenciar o estilo gótico do estilo grego e do estilo egípcio, tanto na fria expressão da pedra como na violenta expressão da alma em sentido transgressor do limite imposto pelo material onde se plasma a vontade da alma. A expressão no gótico tem o infinito como meta, e a inquietação do ser impõe uma transgressão no mundo estático, perfeito e harmônico do estilo grego e na via única para a morte no estilo egípcio. Diferenças estas elencadas pelo próprio Bloch: o Egito “[...] dispõe em camadas, o gótico cria, o Egito imita construtivamente o edifício do universo, o gótico produz simbolicamente o envolvimento, de encontro ao reino anguloso das almas" (BLOCH, S/D, p. 22). Bloch então sintetiza a diferença entre o egípcio e o gótico: enquanto no primeiro impera o signo formal descritivo (deskriptive Formzeichen), no segundo impera o selo formal expressivo-descritivo (expressiv-deskriptive Siegelzeichen). Dada essa diferença, ele pode afirmar o gótico como espírito de ressurreição (Geist der Auferstehung) ${ }^{16}$.

16 Cf. (BLOCH, 1964, p. 38). 
A questão da funcionalidade, neste sentido, ganha outros contornos no gótico, pois existe uma "conformidade com a vida interior" e, para além da vontade de ressurreição, o gótico é para Bloch “[...] o espírito livre do movimento em si mesmo da expressão [...]” (BLOCH, S/D, p. 23), é a vitória, sem negação absoluta, do orgânico sobre o inorgânico. Com isto, determinase a superioridade do gótico, no qual o humano pode se encontrar em movimento em direção ao infinito de expressões interiores moldando o mundo à imagem de sua vida interior. Nesse rumar para o infinito, em que podemos entrever um preenchimento do humano, a metáfora "do deslocamento da floresta para dentro do deserto", não como fim, mas como meio, reflete essa inquietude por transgredir o estático, de fazer florir no seio do humano o Eu utópico capaz de espelhar os sonhos acordados de um mundo melhor. Assim, segundo Francesco Coppellotti, a tese de Bloch do ornamento que expressa o interior do sujeito aponta para um homem estético como objetivo final:

O encontro com o Eu na criação do ornamento implica que o homem estético é dado final, um fato irredutível diante do qual o pensamento deve capitular, a irrupção do irracionalismo na consciência da alma ocidental. $\mathrm{O}$ gosto anuncia o assunto em sua elusiva ausência de responsabilidade, em sua profunda liberdade interior. O homem está sozinho diante de si e, no momento decisivo em que apela ao seu sentimento, toma consciência de sua singularidade. Em todos os outros casos, ele age de acordo com as normas ou se rende a uma realidade objetiva (COPPELLOTTI, 2004, p. XXVIII, tradução nossa). ${ }^{17}$

O gótico aponta o caminho para o alto, aquela primeira descida vertical agora encontra na expressão gótica sua vertical externa, para o alto. A plasticidade com a qual se desenha o gótico, nas palavras de Bloch, reflete nosso estado de inquietude e plasticidade interior, nossa inadequação no mundo. A constante referência ao Eu pode nos enganar, mas, ao contrário do individualismo, Bloch se preocupa com o nós, busca encontrar um caminho para o humano que ainda vem a ser.

\begin{abstract}
Aqui as imagens, conhecidas de modo estranho, podem nos parecer como um espelho mágico no qual podemos ver o nosso futuro, tal como os ornamentos encobertos de nossa figura mais interior, tal como a realização adequada, finalmente percebida, a presença de si daquilo que sempre foi tido como significado, do Eu, do Nós, do tat twam asi (o que tu és) da nossa magnificência que vibra em segredo, da nossa existência divina oculta. É o mesmo que a nostalgia de finalmente ver o semblante humano [...] (BLOCH, S/D, p. 30-31, grifo nosso).
\end{abstract}

17 Esta concepção se assemelha muito à concepção de estética do jovem Bloch, para quem a "[...] definição apriorística da vontade utópica, como renúncia do subjetivo, ansioso, e como constante metafísica de um desejo estético universal, determina a doutrina da arte no espírito da utopia" (MÜNSTER, 1997, p. 128).

\begin{tabular}{|l|l|l|l|l|}
\hline Rovista Dialectus & Ano 10 & n. 21 & Janeiro - Abril 2021 & p. $226-244$
\end{tabular}


Por que Bloch se dedica tanto às análises do egípcio e do gótico? Para ele esses dois modelos de arte foram os únicos a levar até o fim suas experiências estéticas, na medida em que habita neles a constante tensão entre morte e ressurreição. Percebe-se isto mais claramente em O princípio esperança, quando ele retoma esses pontos no capítulo 38, no tópico $O$ Egito ou a utopia do cristal da morte, o gótico ou a utopia da árvore da vida. Pois, "da mesma forma, porém, ambos os símbolos não pairam em absoluto descolados nem são destituídos de um objeto, mas como todos os genuínos, denotam possibilidades reais no mundo, são imagens opostas respondentes a partir de sua latência estética" (BLOCH, 2006a, p. 273). Embora a sacralidade esteja no centro da discussão dos dois modelos, Bloch estava mais preocupado aqui com as utopias arquitetônicas. Diferente disso, no Espírito da utopia ele estava mais interessado no caminho da interioridade para o exterior. Já em $O$ princípio esperança ele aprofunda as diferenças entre o cristal e a árvore da vida. Não há uma negação do estilo egípcio, há um prenúncio utópico de uma arquitetura perfeita, que será referência estética na construção para a posteridade.

[...] enquanto o Egito representa o cristal da morte como perfeição pressentida, com a mesma determinação o gótico está relacionado utopicamente à ressurreição e à vida. Em decorrência, seu símbolo arquitetônico é necessariamente expulsar a morte antimorte, é árvore da vida como perfeição planejada, reproduzida em forma de Cristo. Enquanto a arte egípcia traz dentro de si um querer vir a ser como pedra, a gótica traz um querer vir a ser como a árvore da vida, como videira de Cristo. Ambos os estilos arquitetônicos foram os únicos a ir radicalmente até o fim nessa sua imitação (BLOCH, 2006a, p. 279, grifo nosso).

O gótico quando alcança a metáfora da árvore da vida ultrapassa a frieza do mundo denunciada no Espírito da utopia. Assim, na estética blochiana, o gótico ganha relevância na medida em que a vontade utópica já não é apenas pura subjetivação, mas planejamento de um mundo melhor e transgressão de limites. Essa perspectiva nos abre possibilidades de repensar o gótico nas artes contemporâneas para além de seu lugar privilegiado de análise: a Arquitetura.

\section{REFERÊNCIAS}

ADORNO, Th. W. El asa, la jarra y la experiencia temprana. In: Notas sobre literatura. Traducción: Alfredo Brotons Muñoz. Madrid. Ediciones Akal, 2003. (Obra completa, 11).

BLOCH, Ernst. O princípio esperança. Vol. I. Trad. Nélio Schneider. Rio de Janeiro: EDUERJ: Contraponto, 2005. 
BLOCH, Ernst. O princípio esperança. Vol. II. Trad. Werner Fuchs. Rio de Janeiro: EDUERJ: Contraponto, 2006a.

BLOCH, Ernst. Geist der Utopie: zweiten Fassung von 1923. Frankfurt am Main: Suhrkamp Verlag, 1964.

BLOCH, Ernst. Geist der Utopie: erest Fassung, 1918, Munich-Leipzig, Duncker \& Humblot, 1918. Frankfurt am Main: Suhrkamp Verlag, 1971.

BLOCH, Ernst. Spirito dell'utopia. Traduzione di Vera Bertolino e Francesco Coppellotti. La nuova Italia Editrice, Scandicci, Frienze, milano. 2004.

BLOCH, Ernst. Espírito da utopia. Trad. de Oliver Tolle. Editora 34, São Paulo, no prelo, S/D.

BLOCH, Ernst. Rêve diurne, station debout \& utopie concrete: Ernst Bloch en dialogue. Lignes. Nice, 2016.

BLOCH, Ernst. "Symbole: les Juifs": un chapitre 'oublié de L'Esprit de l'utopie. Trad, Raphaël Lellouche. Précédé de Les Juifs dans l'utopie: Le jeune Bloch, du crypto-franlisme au néomarcionisme par Raphaël Lellouche. Éditions de l'éclat, Paris-Tel Aviv, 2009.

BOLDYREV, Ivan. Geist der Utopie, der sich erst bildet: vorläufige Beobachtungen zur Korrektur des Blochschen Frühwerks. In: Vidal F. (Hrsg.) Bloch-Jahrbuch 2012. Einblicke in Blochsche Philosophie. Mössingen-Talheim: Talheimer Verlag, 2012.

BOLDYREV, Ivan. O Espírito da utopia, que primeiro se forma: observações provisórias para a correção da obra juvenil de Bloch. In: RODRIGUES, Ubiratane de Morais (Org.). Escritos sobre o Espírito da utopia de Ernst Bloch. Porto Alegre, RS: Editora Fi, 2019. 284p. Disponível em: < https://www.editorafi.org/628bloch $>$.

BOURETZ, Pierre. Testemunhas do futuro: filosofia e messianismo. Trad. br. de J. Guinsburg et al. São Paulo: Perspectiva, 2011.

COPPELLOTTI, Francesco. Estética e metareligione per la filosofia futura dell'Europa. In: BLOCH, Ernst. Spirito dell'utopia. Traduzione di Vera Bertolino e Francesco Coppellotti. Frienze: La Nuova Italia Editrice, 2004.

GOETHE INSTITUT. Ernst Bloch et Georg Lukács: un siècle après. Paris: Actes du colloque Goethe Institut, 1985.

HEGEL, G. W. Cursos de Estética. Vol. I. São Paulo: Edusp, 2001. .

HUDSON, Wayne. The marxist philosophy of Ernst Bloch. London: Palgrave Macmillan UK, 1982.

KARADI, Eva. Bloch et lukács dans le cercle de Weber. In: GOETHE INSTITUT. Ernst Bloch et Georg Lukács: un siècle après. Paris: Actes du colloque Goethe Institut, 1985.

\begin{tabular}{|l|l|l|l|l|}
\hline Qenista Dialectus & Ano 10 & n. 21 & Janeiro - Abril 2021 & p. $226-244$ \\
\hline
\end{tabular}


LELLOUCHE, Raphaël. Les Juifs dans l'utopie: Le jeune Bloch, du crypto-franlisme au néomarcionisme. In: BLOCH, Ernst. "Symbole: les Juifs": un chapitre oublié de L'Esprit de l'utopie. Trad, Raphaël Lellouche. Précédé de Les Juifs dans l'utopie: Le jeune Bloch, du crypto-franlisme au néomarcionisme par Raphaël Lellouche. Éditions de l'éclat, Paris-Tel Aviv, 2009.

LOUREIRO, Isabel. A Revolução Alemã, 1918-1923. São Paulo: Editora Unesp, 2005.

MACHADO, Carlos Eduardo Jordão. "Uma filosofia expressionista: sobre o espírito da Utopia”. In: Capítulos do Marxismo Ocidental. Org. Isabel Loureiro e Ricardo Musse. São Paulo: Ed. Unesp, 2001.

MACHADO, Carlos Eduardo Jordão. Um capítulo da história da modernidade estética: Debate sobre o expressionismo (Ernst Bloch, Hanss Eisler, Georg Lukács e Bertolt Brecht). $2^{a}$ edição. São Paulo: Unesp, 2016.

MACIEL, Marta Maria Aragão. Ernst Bloch e Walter Benjamin: reflexões acerca das afinidades eletivas. In: Problemata: R. Intern. Fil. v. 10. n. 4. 2019, p. 339-359.

MÜNSTER, Arno. Utopia, Messianismo e Apocalipse nas primeiras obras de Ernst Bloch. Trad. br. de Flávio Beno Siebeneichler. São Paulo: UNESP, 1997.

PALMIER, Jean-Michel. En realisant L'esprit de l'utopie ou Prière pour um bom usage d'Ernst Bloch. In: GOETHE INSTITUT. Ernst Bloch et Georg Lukács: un siècle après. Paris: Actes du colloque Goethe Institut, 1985.

RODRIGUES, Ubiratane de Morais (Org.). Escritos sobre o Espírito da utopia de Ernst Bloch. Porto Alegre, RS: Editora Fi, 2019. 284p. Disponível em: <https://www.editorafi.org/628bloch>. 